Estudios Románicos, Volumen 27, 2018, pp. 171-183

ISSN: 0210-491

eISSN: 1989-614X

DOI: https://doi.org/10.6018/ER/346611

\title{
DOUS LOCI CRITICI NAS CANTIGAS DE ESTEVAN DA GUARDA
}

(Two textual critical issues in the cantigas of Estevan de Guarda)

\author{
Manuel Ferreiro* \\ Universidade da Coruña
}

\begin{abstract}
Abtract: Despite the many decades that have passed since the discovery of the cancioneiros of medieval Galician-Portuguese troubadour poetry, and extensive textual analysis of the songbooks during that time, many textual critical questions remain unexplored. The purpose of this article is to provide a solution to two cases of lexical confusion in two cantigas by the $14^{\text {th }}$-century troubadour poet, Estevan de Guarda, in order to re-establish the 'true' transmitted version of each text and provide a closer rendering of the letter and spirit of the original songs.
\end{abstract}

Keywords: Textual critical issues; Galician-Portuguese troubadour poetry; Estevan de Guarda.

Resumo: A pesar dos anos transcorridos desde o descubrimento dos cancioneiros que transmitiron a lírica profana galego-portuguesa e a pesar de todo o traballo realizado no ámbito textual, aínda fican múltiplos loci critici que debemos enfrontar e, no posíbel, clarificar.

Neste artigo pretendemos resolver dúas cuestións de carácter lexical que se localizan en senllas cantigas do trobador posdionisino Estevan da Guarda, para, desta maneira, recuperarmos a lección 'verdadeira' do texto das cantigas, con maior fidelidade á letra e ao espírito dos textos medievais.

Palabras clave: loci critici; trobadorismo galego-portugués; Estevan da Guarda.

No ámbito da lírica profana galego-portuguesa son as cantigas de escarnio e maldizer as composicións que presentan maiores dificultades editoriais. Non por acaso este

${ }^{*}$ Este traballo inscríbese no proxecto de investigación Edición crítica dixital das cantigas de amor (FFI2015-63523-P), subsidiado polo "Ministerio de Economía y Competitividad”. Enderezo para correspondencia: Manuel Ferreiro. Departamento de Letras. Facultade de Filoloxía. Rúa Lisboa 7 - 15008 A Coruña (España) (manuel.ferreiro@udc.gal) 
corpus foi o máis tardiamente editado en conxunto, pois houbo que esperar a 1965 para que aparecese a primeira edición de Manuel Rodrigues Lapa, un paso de xigante á hora de nos enfrontarmos a eses textos.

Porén, no conxunto de máis de catro centenares de cantigas, fican pasos difíciles, problemas por resolver, verdadeiros loci critici que dificultan a comprensión e escurecen o sentido, conscientes de que aínda non estamos perante o texto verdadeiro.

\section{1. *pediolo, *pedrolo vs. Pedrolo}

O primeiro locus criticus que queremos abordar localízase no refrán da cantiga ${ }^{1}$ 1323 / 30,26, transmitida polos dous cancioneiros apógrafos italianos (B1306, V911), onde, en palabras de Lapa, "Estevan da Guarda [...] chasqueia de um casal, que vivia estranhamente; ela, vestindo bem, prostituía-se com outros, e ele obrigava-se a trazer ao colo, chorando miséria, os filhos que não eram seus" (Lapa 1970 [1965]: 170).

Tras a transcrición paleográfica do testemuño de $\mathrm{V}$ realizada por Monaci (1875: 309-310), a composición aparece editada por vez primeira no Cancioneiro Portuguez da Vaticana de Teófilo Braga (1878: 170). Eis a súa versión da primeira estrofa co refrán que nos interesa:
Pois a todos avorrece
este jograr avorrido,
de tal molher e marido
que a min razon parece
de trager per seu pediolo
o filho d'outro no colo.

Para alén da deficiente sintaxe da estrofa que se percibe neste e nos seguintes editores, a cuestión radica no termo que Braga recolle directamente de $\mathrm{V}$, pediolo $(<$ pedrolo $>$ $\mathrm{B},<$ pediolo $>$ V), e que define no "Glossário" da edición como 'Peditorio', isto é, 'acto de pedir esmola' (Braga 1878: 235).

Pola súa parte, na edición semidiplomática do Cancioneiro da Biblioteca Nacional de José Pedro Machado e Elsa Paxeco Machado aparece o mesmo pediolo no refrán, cunha proposta textual aínda máis discutíbel (Machado; Machado 1958: VI, 30-31), feito de que os editores son conscientes, pois no Glossário (Machado; Machado 1964: VIII, 399, s.v. pediolo) explicitan as dúbidas semánticas, preguntándose se a súa significación é "piolho":
Pois a todos auorrece
Este iog ar auorrido
De tal molher e marido,

$1 \quad$ Para as referencias ás cantigas utilizamos o sistema de Jean Marie D’Heur (1975: 10-93), coas correccións achegadas por Montero Santalla (2000: 55-101), xunto coa numeración do Repertorio metrico de Tavani (1967); nas referencias abreviadas é utilizada simplemente a numeración d'heuriana seguida do número de verso. 
Que a mjn razon parece,

De trager, por seu pediolo,

O filho d outro no colo.

Realmente, haberá que esperar a Manuel Rodrigues Lapa para nos encontrarmos cun texto editado con rigor e xustificado do punto de vista ecdótico, por máis que as dúbidas continúen (Lapa 1970 [1965]: 170):

Pois a todos avorrece

este rogar avorrido

de tal molher e marido,

que a min razon parece

de trager, por seu pediolo,

o filho doutro no colo.

No Vocabulário Galego-Português anexo á edición lapiana, o grande estudoso portugués indica que pediolo equivale a 'caixa de esmolas, mealheiro', ao tempo que nas notas críticas ao texto xustifica a escolla editorial:

Palavra estranha, não dicionarizada, que nos parece de formação relativamente moderna: pedir + olo, sendo olo um masculino analógico de ola = panela, com o sentido de «púcadro, panelo». Então, pediolo designaria o recipiente que traria a criança na mão, como chamariz da esmola.

Un ano despois, en 1971, Walter Pagani realiza a edición crítica do cancioneiro de Estevan da Guarda e estabelece un texto diferente, especialmente no relativo á voz en causa (1971: 108-109):

Pois a todos avorrece

este lograr avorrido

de tal molher e marido,

que a min razon parece

de trager, por seu pedrolo,

o filho d'outro no colo.

Tras aclarar que por seu pedrolo se debe entender "come suo bimbo, come suo figlio", recolle o comentario crítico de Lapa e xustifica a elección da variante textual pedrolo, a lección trasmitida polo Cancioneiro da Biblioteca Nacional, recoñecendo que non é totalmente "soddisfacente" a proposta: "Preferisco leggere pedrolo e dare al termine il significato attestato da Carré Alvarellos di «niño robusto y vivaracho»; ma anche questa soluzione non è del tutto soddisfacente".

Finalmente, é Graça Videira Lopes quen en 2002 re-edita o cancioneiro escarniño galego-portugués e renova a lectura do texto de Estevan da Guarda (Lopes 2002: 499): 


\begin{abstract}
Pois a todos avorrece
este tal jogar avorrido

de tal molher e marido,

que a mim razom parece

de trager, por seu pedrolo,

o filho d'outro no colo.
\end{abstract}

Nas "Notas complementares" indica que pedrolo significa 'fedelho' (en liña con Pagani); no entanto, recoñece, máis unha vez, que levanta "algumas dúvidas" (Lopes 2002: 596):

Em $\mathrm{B}$ e $\mathrm{V}$ a lição não é clara no grupo que segue o primeiro $<\mathrm{d}>$ (pedido, pedrolo, pediolo?). Quanto à primeira hipótese (pedido), deparamo-nos com o problema da rima, sobretudo na $2^{\mathrm{a}}$ e $3^{\mathrm{a}}$ estrofes; não sendo impossível uma rima imperfeita, penso que não será provável (ainda que semanticamente fosse uma lição sedutora, já que o marido «está mesmo a pedir» o que lhe acontece). Lapa leu pediolo, dando para o termo uma explicação que me parece bastante fantasiosa (pedíolo seria uma espécie de caixa de esmolas, de pedir + olo, sendo o último elemento o masculino de ola, panela), explicação que, além disso, não faz sentido no contexto (não é o marido que anda a pedir, é a mulher que ganha para ele). Decidi-me pela leitura pedrolo, termo que ainda hoje existe em galego com o sentido de rapaz vivaço.

Finalmente, nas Cantigas Medievais Galego-Portuguesas ${ }^{2}$, produto do Projeto Littera en que Lopes é responsábel da parte filolóxica, é recollido o texto de 2002, e reitéranse as dúbidas arredor de pedrolo, que é explicado do seguinte xeito: "O pedrolo, ou pedroulo, é um pequeno inseto, frequente nas vinhas da Galiza e muito voraz. O sentido, aqui, parece ser, no entanto, sobretudo metafórico (fedelho?)". En nota específica a pedrolo novamente se tenta explicar a escolla editorial e as súas dificultades:

O termo só é transcrito na primeira estrofe, e de forma pouco clara: em B, pedrolo (?), em V, pedrõlo (?). Em ambos os casos não seria impossível ler pedido, leitura que parece semanticamente bastante adequada, mas que implicaria um refrão sem rima (sobretudo na segunda e terceira estrofes). A leitura de Lapa, pediolo, além de implicar o mesmo problema, não está dicionarizada, como o próprio reconhece, e parece-nos difícil de justificar (proviria de "pede+ola", e significaria "panela de esmolas"). Assim sendo, e sem solução alternativa à vista, optámos por seguir simplesmente os mss., partindo do princípio que os dois versos do refrão rimam entre si, e entendendo o termo no sentido que tem na Galiza, entre os viticultores".

Até aquí, as propostas editoriais para pediolo (V) / pedrolo (B), baseadas quer en V, cun substantivo, anómalo, derivado de pedir -nunca documentado-, quer en B, cun es-

$2 \mathrm{http} / / /$ cantigas.fcsh.unl.pt/cantiga.asp?cdcant=1336\&tr $=4 \& \mathrm{pv}=\operatorname{sim}$ 
traño uso metafórico a partir dunha voz agraria rexistrada por vez primeira en Martín Sarmiento (véxase RILG, s.v. pedrolo) ${ }^{3}$.

Fronte a estas propostas, acreditamos en que a solución editorial para este locus criticus provén de considerar pedrolo en relación co nome do protagonista masculino da cantiga, Pero da Arruda, conforme se explicita na estrofa III:

\author{
Como Pero da Arruda \\ foi da molher ajudado, \\ non é mui desaguisado, \\ pois lh'esta faz tal ajuda, \\ de trager, ...
}

No corpus trobadoresco galego-portugués é constante a alternancia entre Pero e Pedro (do lat. Petrus) como nome de pía de diversos personaxes e trobadores. Deste xeito, achamos Pedro Bodinho e Pero Bodinho, un personaxe sen identificar, presente en senllas cantigas de Pero da Ponte e Pedr'Amigo de Sevilha': Seja-o Pedro Bodinho, I que éste nosso vezinho / tamben come Pedr'Agudo (1658.5); pero s[e] eu con el cantar I e Pero Bodin[h]'outrossi / e quantos cantadores son (1680.18). Tamén se rexistra alternancia entre Pero Bõo e Pedro Boo, outro personaxe citado en cadansúa cantiga de Pero Garcia d'Ambroa e de Pero Garcia Burgales: De Pero Bõo and'ora espantado / de como era valent'e ligeiro, I e vivedoir'é as [s] az, e arrizado (1585.1); de Pedro Boo, que era arrizado / e ben manceb'assaz pera viver (1390.3).

Por outra banda, no relativo ao nome de trobadores, tanto Pero Garcia Burgales como Pero d'Armea e Pero da Ponte son citados coa forma Pero cando aparece o seu nome completo (ou parcialmente completo); así, o Burgalés comparece nas cantigas como Pero Garcia: Pero Garcia, non poss'eu saber / como vos vós possades emparar I d'amor (1401.8); Pero Garcia, sempr'oi dizer / que os conselhos boos boos son (1401.22); Quero que julguedes, Pero Garcia, I d'antre min e todo-los trobadores I que de meu trobar son desdezidores (1444.1); Pero Garcia me disse / que mia senhor con el visse (1480.1); "A[i] Pero Garcia, / gran med[o] ei de Dona Maria, I que nos mataria» (1480.4); Mal conhocedes Dona Maria, / ai Pero Garcia! (1480.20).

Tamén Pero d'Armea, é así nomeado nunha cantiga de Pero Garcia d'Ambroa: Pero d'Armea, quando composestes / o vosso cuu, que tan ben parescesse (1613.1).

E o mesmo acontece con Pero da Ponte, citado en composicións da autoría de Afonso X: Pero da Pont'á feito gran pecado / de seus cantares, que el foi furtar / a Coton (483.1); E por én foi Coton mal dia nado, / pois Pero da Ponte erda seu trobar 483.8); Pero da Ponte, paro-vos sinal / per ante o demo do fogo infernal (485.1). Tamén nunha tençon con Afons'Eanes do Coton, que sempre se refire a el como Pero da Ponte (971.1, 15 e 29) e noutra con Garcia Martiiz, que tamén o interpela da mesma forma (1664.9, 25 e 37). E finalmente aínda este trobador galego volve aparecer citado por Afons'Eanes do

\footnotetext{
3 No estudo sobre as rimas da poesía trobadoresca galego-portuguesa, neste caso Montero Santalla (2000: 618) inclínase, cun interrogante, por pediolo como palabra rimante.

4 Todas as ocorrencias e contextos foron tirados de GLOSSA.
} 
Coton: Pero da Ponte, ou eu non vejo ben, I o[u] [de] pran essa cabeça non é / a que vós antano, per bõa fe, I levastes quando fomos a Geen (1626.1); quen visse Pero da Ponte en cos, / semelhar-lh'-ia moi peor talhado (1627.6).

Fronte a estas denominacións, en todos os casos aparece don Pedro para se referir a estes tres trobadores en contextos en que só aparece o nome de pía. Así acontece con Pero Garcia Burgales: Don Pedro, en como vos ouç’i falar, I [o] u ja vós ben non sabedes julgar, I ou dos outros ofereçon avedes (1444.15).

E con Pero d'Armea: E, Don Pedro, põede-lh'os narizes, / ca vos conselh'eu o melhor que poss[o] (1613.8); E, Don Pedro, os beiços lh'er põede / a esse cuu, que é tan ben barvado (1613.15).

Finalmente, Pero da Ponte (483.12) pois que se de quant'el foi lazerar / serve Don Pedro e non lhi dá én grado (483.14) E con dereito seer enforcado / deve Don Pedro porque foi filhar I a Coton, ..., I seus cantares (485.19) E por én, Don Pedr', e [n] Vila Real I en mao ponto vós tanto bevestes.

En consecuencia, estabelecida a equivalencia e, sobre todo, a alternancia entre as formas Pedro e Pero, feito constante, por outra parte, nos textos medievais de calquera tipo, fica o problema dun sufixo -olo, aparentemente ausente nos textos antigos e sen uso no portugués contemporáneo.

No entanto, é ben coñecida a composición 354 das Cantigas de Santa Maria, «Como Santa Maria guardou de morte hũa bestiola que chaman donezỹa» (Mettmann 1989: III, 218):

Este pesar foi por hũa | bestiola que muit'amava

el rei, que sigo tragia | e que mui ben criava, a que chaman donezỹa $\mid$ os galegos, e tirava con ela aves das covas, $\mid$ e de taes ome vee.

A voz bestiola (< bestia + -ola) presenta indubitabelmente o sufixo -olo/-ola cun carácter basicamente diminutivo (levemente depreciativo), o mesmo que sobrevive en galego moderno, onde este sufixo é utilizado en rexistros fundamentalmente familiares e/ ou coloquiais, cunha "relativa produtividade sobre bases nominais, normalmente substantivas" (Ferreiro 2001 [1997]: 187): amigolo ( $<$ amigo + -olo), barrigola $(<$ barriga + -ola), merendola $(<$ merenda + -ola), raiola $($ e raiolo $)(<$ raio + -ola $)$, rapazolo $(<$ rapaz + -olo), sachola $(<$ sacho +-ola) etc.

En calquera caso, a voz bestiola parece suxerir unha orixe inicialmente erudita do sufixo, utilizado sobre unha base latinizante (bestia) que contrasta cos resultados medievais evoluídos a partir do lat. BestiAm: bescha (arc.) e besta.

Porén, para alén da súa aparición nas cantigas marianas, a procura deste sufixo en textos medievais confirma que -olo/-ola tiña certa presenza na lingua, pois achamos nos textos prosísticos tres ocorrencias do antecitado sufixo en documentos notariais do século $\mathrm{XV}^{5}$. A primeira delas prodúcese no documento de 1414, de Ferreira de Pantón, na voz matolla $(<$ mata + -ola), un diminutivo de mata 'arbusto':

$5 \quad$ As diversas ocorrencias lexicais nos textos galegos foron localizadas a través do TMILG. 
et estes sete annos pasados que diades terça do viño segundo dito he, et lle roçedes as matollas e os lomideyros et non leyxedes en ellas creçer monte, et que diades de cada hun anno ós capelaãs do dito mosteiro çinquo quartillos de viño de renda por día de San Martino de novembro et tres soldos ó dito monesteiro porllo dito día de Samartino (Fernández de Viana y Vieites 1995: 149).

As outras dúas aparicións prodúcense na voz sayolla (saio saia + -ola), diminutivo de saia ou saio, en dous documentos ourensáns algo máis tardíos, de mediados do século XV. A primeira ocorrencia, en 1455:

Hun gibón nouo, de fustán, con a meatade de huas sayollas et outro saquillo de pano, forrado en branco, et tres çintas descoadra; cinqo bulsas et dous esqeiros; tres pares de canybetes; hun papel de cordóos (Ferro Couselo 1967: I, 315).

A segunda, nun documento de 1458:

Et mays prometeu o dito meestre Daniyel ao dito Lourenço, ferreiro, que, dándolle os ditos noueçentos ferros feitos enos ditos quatro meses, que lle daría hua capa de boo pano et huas sayollas et hun gibón et huas calças et hun bonete et hua camisa et hun par de panetes e huus çapatos (Ferro Couselo 1967: I, 438).

Con todo, noutro documento de Ferreira de Pantón do mesmo período que o antes citado (do ano 1420) rexístrase a variante matela exactamente co mesmo uso que o anterior matola:

E aforámolas con súas entradas et seydas per ut quer que vaan, que lle roçedes as matelas e non leyxedes en elas cresér o monte et as entrechantedes hu for mester (Fernández de Viana y Vieites 1995: 175).

Certamente, a convivencia matola matela suxire que o sufixo -olol-ola ben pode ser unha variante especializada do antigo sufixo diminutivo -elo/-ela, que sobrevive tamén en galego con rendibilidade limitada á sombra do poderoso -iño/-iña (véxase Ferreiro 2001 [1997]: 185-186).

Deste xeito, na cantiga de Estevan da Guarda estariamos perante unha forma diminutiva que afecta a un nome propio (Pero $\sim$ Pedro $\rightarrow$ Pedrolo), que tamén encontra apoio nos usos antigos, pois a forma Sancholo $(<$ Sancho +- -olo) aparece na tradución galega da Crónica de Castilla e da Estoria de España (século XIV):

Andados iij ãnos do rreynado del rey dõ Afonso de Leõ -et foy esto ẽna era [de] $M$ et XX ãnos - este Abderrahme, de que ora aqui dissemos, segũdo conta a estoria, era chamado por iogo Sancholo (Lorenzo 1975: I, 225). 
Este mesmo antropónimo en forma diminutiva aparece tamén na documentación notarial galega, como demostra a seguinte pasaxe dunha carta de 1419, do territorio mindoniense:

Et por que seia certo, mando vos delo faser huna carta, a mays çerta que se pode faser, por lo dito notario et testemoyas que foron presentes: frey Roy Gomes; et Afonso Peres de Abadin; Roy Garçia Sancholo; et Garçia Lopes, pyntor, et outros (Graña Cid 1990: 289).

E en territorio portugués podemos achar a mesma forma Sancholo na máis tardía Crónica Geral de Espanha de 1344:

De como Abderame foi rey de Cordova e em como o matarom Andados dous annos do reynado daquelle rey dom Afõsso - e foy esto na era de mil e viinte ãnos - este Abderame de que avemos dito, segundo delle conta a estorya, era chamado come por jogo d'escarnho Sanchollo. E foy homen maao e travesso e, esso que elle ẽno reynado durou, nõ se trabalhava tanto doutra cousa como de molheres e de vynho, assy que era muy luxurioso e bevodo (Cintra 1961: III, 194).

Desta forma, se na cantiga de Estevan da Guarda se estabelece jogar no v. 2, única lectura posíbel de $<\operatorname{iogar}>\mathrm{B},<\operatorname{iog} u a r>V$, e, sobre todo, consideramos a presenza da forma verbal é no v. 3 (interpretada como copulativa en todas as edicións) para confirmar a existencia dun verbo principal na primeira estrofa, o texto escarniño fica esclarecido coa alusión a Pedrolo, isto é, Pedriño, suposto fillo de Pero da Arruda, produto da infidelidade de súa muller:

Pois a todos avorrece

este jogar avorrido, de tal molher é marido, que a min razon parece de trager, por seu Pedrolo, o filho d'outro no colo.

Pois ela trage camisa de sirgo tan ben lavrada e vai a cada pousada por algo, non é sen guisa de trager, [por seu Pedrolo, o filho d'outro no colo ]. 
Como Pero da Arruda

foi da molher ajudado, non é mui desaguisado, pois lh'esta faz tal ajuda, de trager, [por seu Pedrolo, o filho d'outro no colo].

\section{2. *encividade vs. ensibidade}

Noutra cantiga, tamén escarniña, de Estevan da Guarda (1326 / 30,28 «Pois que te preças d'aver sén comprido» [B1309/V914] $]^{6}$ ) aparece outro locus criticus pola interpretación das leccións manuscritas <ensy vidade $>\mathrm{B}$, <ensy uitade $>\mathrm{V}$ no v. 8, editadas como en cividade na primeira edición "crítica" desta composición da autoría de Braga (1878: 171), após a edición paleográfica de V realizada por Monaci (1875: 311). O erudito portugués erra claramente na edición da pasaxe, interpretando o segundo elemento como unha forma arcaica de cidade (tal como explicita no «Glossario Archaico do Cancioneiro» con que cerra a súa edición):
Ca sempre contam por en cyvidade ao pastor por dar-sse de gram sen, nem gram saber, por end'a ty conven en quanto es tam pastor d'idade, pois en tan alta razon ousas que punhes sempre antre outras cousas seeres partido de torpidade.

Na seguinte versión -semidiplomática- da cantiga, realizada polos Machado (1958: VI, 33-34), aparece a forma literal de B xunto con outras múltiplas interpretacións erradas e incorreccións de lectura na estrofa:

Ca sempre contam por ensyvidade

Ao pastor preçar sse de gram ssem,

Nen gram saber, por edace, couem

Enquanto es tan pastor d idade;

Por gent am alta razon ousas,

Que punhes senpr antr as outras cousas

Seeres partido de torpidade.

A voz ensyvidade é explicada no glosario dos Machado como 'incivilidade, falta de educação’ (1964: VIII, s.v.).

\footnotetext{
6 Coa seguinte rúbrica: «Esta cantiga foi feita a ũu galego que se preçava de trobar e non o sabia ben, e meteu-s'a maneira de tençon con [E]stevan da Guarda, e 'Stevan lhi fez esta cantig'; e el andava sempre espartido, e nunca lhe entendeu a cantiga nen lhe soube a ela tornar».
} 
Como acontece con todos os textos escarniños, é a compilación lapiana a que formaliza a 'vulgata' das cantigas de escarnio e maldizer, cun texto que vai ser repetido sistematicamente (Lapa 1970 [1965]: 171):
Ca sempre contan por encividade
ao pastor preçar-se de gran sen
nen gran saber; porend' a ti conven,
enquanto és atan pastor d' idade,
pois en tan alta razon tan muit' ousas,
que punhes sempre, antr' as outras cousas,
en seeres partido de torpidade.

As explicacións do grande erudito portugués continúan a insistir neste suposto derivado do lat. InCIVILITATEM ( $>$ *enciviidade), aínda que tamén apunta a un eventual "erro do copista, por endinidade, que seria forma mais corrente". E despois, no «Vocabulário Galego-Português», a voz *encividade é definida como "incivilidade, despropósito" (p. 38).

O texto lapiano perdura na edición crítica de Pagani (1971: 116-117), que xustifica a proposta textual nos mesmos termos que Lapa, igual que acontece coa edición de Graça Videira Lopes (2002: 502-503), que tamén fai equivaler encividade a 'incivilidade, descortesia'.

No entanto, xa no ano 2000, Montero Santalla propuxera unha interpretación alternativa para esa pasaxe da cantiga, a través da voz ensabidade 'ignorancia, esquecemento, falta de saber' a partir da súa documentación no Elucidário de Viterbo coa forma insabidade (Montero Santalla 2000: 619).

Con efecto, tal forma ten rexistro indirecto a través de Viterbo (1966: II, s.v. insabidade); porén, agora podemos confirmar a existencia desta voz, que achamos no Tratado de Confissom, obra doutrinaria traducida no século XV en Portugal: "Item quẽ iura na cruz nõ sagrada, huũ ano de peendença e se iura per insibidade ou por costrãgimento, tres anos de pe ̃̃demça" (Machado 2003-2013: 39).

Por conseguinte, a partir de <ensy vidade $>\mathrm{B},<$ ensy uitade $>\mathrm{V}$, a única interpretación posíbel desta pasaxe problemática de Estevan da Guarda será ensibidade con perfecta coherencia semántica e xustificación paleográfica a partir dalgúns erros de copia nos apógrafos italianos.

En primeiro lugar, podemos documentar o erro $\langle\mathrm{u}>\sim<\mathrm{v}\rangle \mid<\mathrm{b}>$ ao longo do Cancioneiro da Biblioteca Nacional e mais do Cancioneiro da Vaticana: <savor $>$ B sabor (114.17), < $<\widetilde{\mathrm{e}}>\mathrm{B}$ ben (205.2), <uen $>\mathrm{V}$ ben (884.3), <traualhe $>\mathrm{V}$ trabalh'e (1348.19), <ueeyro> V Beeito (1484.1), <ueeyto> V Beeito (1484.3), <velpelho> V Belpelho (1489.1) etc. E do mesmo xeito nestes dous cancioneiros é frecuente a confusión $<\mathrm{t}>|<\mathrm{d}\rangle$, nomeadamente no Cancioneiro da Vaticana, de onde extraemos algúns exemplos como mostra: < pagado $>\mathrm{B},<$ pagato $>$ V pagado $(828.12),<$ p $^{\mathrm{i} u a d} 9>\mathrm{B}$, $<$ priuatus $>\mathrm{V}(879.2),<$ poder $>\mathrm{AB},<$ poter $>\mathrm{V}$ poder $(901.10)$, < iulgade $>\mathrm{B}$, < uilgate $>$ $\mathrm{V}$ julgade (1019.13), < dal $>\mathrm{B},<\mathrm{tal}>\mathrm{V}$ d'al (1227.19) etc. 
Finalmente, os dicionarios portugueses antigos que recollen este termo, sempre baixo a forma insabidade, son coincidentes en lle atribuír o valor de 'ignorancia' ao tempo que o cualifican sistematicamente de voz antiga ou anticuada (véxanse, por exemplo, Bluteau 1712-1721, Silva 1789, Vieira 1871-1874 ou Figueiredo 1978 [1939]).

A partir dos datos precedentes, semella obvio que a lectura certa da pasaxe en causa é ensibidade, con plausabilidade paleográfica e adecuación semántica perfecta:

Pois que te preças d'aver sén comprido en trobar ben e en bõa razon, non faz mester a ti, Fernan Chancon, d'ir entençar come torpe avurrido nen te loares come quen s'engana, e de palavras torpes e d'oufana e de posfaço seer espartido,

ca sempre contan por ensibidade ao pastor preçar-se de gran sén nen gran saber; por end'a ti conven, enquanto es [a]tan pastor d'idade, pois en tan alta razon [tanto] ousas, que punhes sempre, antr'as outras cousas, seeres partido de torpidade. [vv. 1-14]

\section{BIBLIOGRAFÍA}

BLUTEAU, Raphael (1712-1721): Vocabulario Portuguez, e Latino... Coimbra: No Collegio das Artes da Companhia de JESU [8 vols.].

BRAGA, Teófilo (1878): Cancioneiro Portuguez da Vaticana. Edição critica restituida sobre o texto diplomatico de Halle. Lisboa: Imprensa Nacional.

CINTRA, Luís Filipe Lindley (ed.) (1952-1990): Crónica Geral de Espanha de 1344. Lisboa: Imprensa Nacional - Casa da Moeda [4 vols.].

D'HEUR, Jean Marie (1975): Recherches internes sur la lyrique amoureuse des troubadours galiciens-portugais (XII ${ }^{e}-X I V^{e}$ siècle): contribution à l'étude du «corpus des troubadours». Liège: Université de Liège.

FERNÁNDEZ de VIANA y VIEITES, José Ignacio (ed.) (1995): Colección diplomática del monasterio de Santa María de Pantón. Lugo: Deputación de Lugo.

FERREIRO, Manuel (2001 [1997]): Gramática histórica galega. II. Lexicoloxía. Santiago de Compostela: Laiovento.

FERRO COUSELO, Xesús (ed.) (1967): A vida e a fala dos devanceiros. Escolma de documentos en galego dos séculos XIII ao XVI. Vigo: Galaxia [2 vols.].

FIGUEIREDO, Cândido de (1978 [1939]): Grande Dicionário da Língua Portuguesa. Lisboa: Livraria Bertrand [2 vols.]. 
GLOSSA = Ferreiro, Manuel (dir.) (2014-): Glosario da poesía medieval galego-portuguesa. Universidade da Coruña [http://glossa.gal].

GRAÑA CID, M. Mar (ed.) (1990): "Las órdenes mendicantes en el obispado de Mondoñedo. El convento de san Martín de Villaoriente (1374-1500)". Estudios Mindonienses. 6: 13-464.

LAPA, Manuel Rodrigues (1970 [1965]): Cantigas d'Escarnho e de Mal Dizer dos Cancioneiros Medievais Galego-Portugueses. Vigo: Galaxia.

LITTERA = Lopes, Graça Videira; FERREIRA, Manuel Pedro et alii (2011-), Cantigas Medievais Galego Portuguesas [base de dados online]. Lisboa: Instituto de Estudos Medievais, FCSH/NOVA [http://cantigas.fcsh.unl.pt].

LOPES, Graça Videira (2002): Cantigas de Escárnio e Maldizer dos Trovadores e Jograis Galego-Portugueses. Lisboa: Estampa.

LORENZO, Ramón (1975): Traducción gallega de la Crónica General y de la Crónica de Castilla. Vol. I. Introducción, texto anotado e índice onomástico. II. Glosario. Ourense: Instituto de Estudios Orensanos «Padre Feijoo».

MACHADO, José Barbosa (ed.) (2003-2013): Tratado de Confissom [Chaves, 1489]. Braga: Edições Vercial.

MACHADO, Elsa Paxeco; MACHADO, José Pedro (1949-1964): Cancioneiro da Biblioteca Nacional, antigo Colocci-Brancuti. Lisboa: Edição da Revista de Portugal [8 vols.].

METTMANN, Walter (ed.) (1986-1989), Alfonso X el Sabio, Cantigas de Santa Maria. Madrid: Castalia [3 vols.].

MONACI, Ernesto (1875): Il canzoniere portoghese della Biblioteca Vaticana. Halle a.S.: Max Niemeyer Editore.

MONTERO SANTALLA, José-Martín (2000): As Rimas da Poesia Trovadoresca Galego-Portuguesa: Catálogo e Análise, Tese de Doutoramento (inédita), Universidade da Coruña [3 vols.].

PAGANI, Walter (1971): «Il Canzoniere di Estevan da Guarda», Studi Mediolatini e Volgari. XIX: 53-179.

RILG = Recursos Integrados da Lingua Galega . Seminario de Lingüística Informática Grupo TALG / Instituto da Lingua Galega [http://sli.uvigo.es/RILG/].

SILVA, Antonio de Morais (1789): Diccionario da Lingua Portugueza ... Lisboa: Na officina de Simão Thaddeo Ferreira [2 vols.].

TAVANI, Giuseppe (1967): Repertorio metrico della lirica galego-portoghese. Roma: Edizioni dell'Ateneo.

TMILG = Varela Barreiro, Xavier (dir.): Tesouro Medieval Informatizado da Lingua Galega . Santiago de Compostela: Instituto da Lingua Galega [http://ilg.usc.es/tmilg].

VIEIRA, Domingos (1871-1874): Grande Diccionario Portuguez ou Tesouro da Lingua Portugueza. Porto: En Casa dos Editores Ernesto Cilardron e Bartholomeu H. de Moraes [5 vols.]

VITERBO, Fr. Joaquim de Santa Rosa (1965-1966): Vocabulário das palavras, termos e frases que em Portugal antigamente se usaram e hoje regularmente se ignoram. Ed. crítica por Mário Fiúza. Porto: Livraria Civilização Editora [2 vols.]. 


\section{PERFIL ACADÉMICO Y PROFESIONAL}

Manuel Ferreiro es licenciado (1978) y doctor (1990) en Filología Hispánica (subsección: Gallego-Portugués) por la Universidade de Santiago de Compostela. Actualmente es catedrático de Filologías Gallega y Portuguesa en la Universidade da Coruña.

Su actividad investigadora se reparte entre la Lingüística Histórica y la Ecdótica y Crítica Textual: los dos volúmenes de la Gramática Histórica Galega (1995-1997, $1^{\text {a }}$ ed.) se inscriben en la primera línea de investigación; con el segundo núcleo de pesquisa están relacionados los trabajos que tienen como objeto el estudio y edición de textos medievales, en especial los textos trovadorescos gallego-portugueses, con participación y dirección de proyectos de investigación, junto con la publicación de contribuciones y artículos especializados en revistas y libros colectivos, así como monografías como $A s$ cantigas de Rodrigu'Eanes de Vasconcelos (1991) o O Cancioneiro de Pero Mafaldo (2014, en colab. con Leticia Eirín).

La figura y la obra de Eduardo Pondal constituye otro centro de interés investigador en el ámbito de la Crítica Textual e del estudio de la lengua literaria pondaliana, con la publicación de múltiples estudios, especialmente los cuatro tomos de su obra completa (1995-2005) y numerosos trabajos y monografías sobre el poeta: De Breogán aos Pinos. O texto do Himno Galego, 1996, $1^{\text {a }}$ ed.; O Himno Galego. Documentos históricos 18901907 (2007); Eduardo Pondal, o cantor do eido noso (2017); Estes son os eidos amigos. Escolma xeográfica da poesía pondaliana (2017); Eduardo Pondal: Os cantos eran da Patria (120 poemas) (2017).

En 2006 obtuvo el XVII Premio de Investigación "Losada Diéguez" por la edición del poema épico Os Eoas, y en 2014 le fue concedido el IX Premio de Investigación "Concepción Arenal" de Humanidades por el proyecto Glosario da poesía medieval profana galego-portuguesa (www.glossa.gal).

Actualmente dirige el proyecto Universo Cantigas, que tiene como objetivo realizar la edición crítica digital de los textos que integran la lírica profana gallego-portuguesa (www.universocantigas.gal).

Fecha de recepción: 12/05/2018

Fecha de aceptación: 17-5-2018 